\title{
RESPOSTA DE CULTIVARES DE ARROZ-DE-SEQUEIRO À CALAGEM ${ }^{(1)}$
}

\author{
AILDSON PEREIRA DUARTE ${ }^{(2)}$, RACHEL BENETTI QUEIROZ-VOLTAN ${ }^{(3)}$, \\ PEDRO ROBERTO FURLANI ${ }^{(4,5)} \&$ RICARDO AUGUSTO DIAS KANTHACK ${ }^{(2)}$
}

\begin{abstract}
RESUMO
Desenvolveu-se um experimento de campo, em Assis (SP), em areia quartzosa com capacidade de troca de cátions igual a $35 \mathrm{mmol}_{\mathrm{c}} \cdot \mathrm{dm}^{-3}$ e $9 \%$ de saturação por bases. Estudou-se a resposta dos cultivares de arroz-de-sequeiro (Oryza sativa L.) IAC 25, IAC 47, IAC 165 e Araguaia às doses $0,2,4$ e 6 t.ha ${ }^{-1}$ de calcário dolomítico e 2 t.ha ${ }^{-1}$ de calcítico. O calcário foi aplicado em outubro de 1991 e as avaliações, realizadas no ano agrícola 1992/93. Aos 20 dias da emergência das plantas, amostrou-se a parte aérea para análises de macro- e de micronutrientes e, aos 40 dias, coletaram-se raízes para estudos anatômicos. Dois anos após a calagem, a maior saturação por bases do solo foi apenas de $55 \%$. A estrutura anatômica das raízes permaneceu inalterada com a calagem, ocorrendo as diferenças somente na razão entre as medidas do córtex e do cilindro vascular. O cultivar IAC 165 foi o único a não aumentar a produção de massa verde da parte aérea e a diminuir a relação córtex/cilindro vascular das raízes com as doses de calcário. A calagem reduziu os altos teores de manganês nas plantas, os quais estavam associados ao encharcamento temporário do solo; reduziu, também, os teores de fósforo, potássio e zinco, aumentando os de nitrogênio, cálcio, magnésio e ferro. Verificou-se maior produção de massa verde da parte aérea quando se aplicou calcário dolomítico em
\end{abstract}

\footnotetext{
${ }^{(1)}$ Recebido para publicação em 2 de dezembro de 1998 e aceito em 26 de maio de 1999.

(2) Núcleo de Agronomia do Vale do Paranapanema, Instituto Agronômico (IAC), Caixa Postal 263, 19800-000 Assis (SP).

${ }^{(3)}$ Centro de Recursos Genéticos Vegetais e Jardim Botânico, Instituto Agronômico (IAC), Caixa Postal 28, 13001-970 Campinas (SP).

(4) Centro de Solos e Recursos Agroambientais, IAC.

${ }^{(5)}$ Com bolsa de produtividade em pesquisa do CNPq.
} 
comparação ao calcítico, exceto no 'IAC 47'. Todos os cultivares apresentaram maiores teores de magnésio e menores de cálcio quando tratados com calcário dolomítico em comparação ao calcítico. Concluiu-se que, para cultivo de arroz nessa areia quartzosa, em sistema de renovação de pastagens, deve-se fazer a calagem com calcário dolomítico para correção da acidez e fornecimento do magnésio.

Termos de indexação: arroz-de-sequeiro, Oryza sativa L., anatomia de raiz, cálcio, magnésio.

\section{ABSTRACT UPLAND RICE CULTIVARS RESPONSE TO LIMING}

A field experiment was laid out in a quartz sandy soil (Quartzipsamment) in Assis, State of São Paulo, Brazil, having cation exchange capacity of $35 \mathrm{mmol}_{\mathrm{c}} \cdot \mathrm{dm}^{-3}$ and $9 \%$ base saturation. The differential response of the upland rice cultivars IAC 25, IAC 47, IAC 165 and Araguaia to the rates of 0, 2, 4 e 6 t.ha $^{-1}$ of dolomitic and 2 t.ha $^{-1}$ of calcitic limestone as additional treatment was evaluated. The limestone was applied in October of 1991 and the evaluations were carried out during the 1992-93 growth period. Twenty days after the plant emergence, the shoots were sampled for nutrient chemical analysis and twenty days later roots were sampled for anatomical studies. Two years after liming the largest base saturation was only $55 \%$. The root structure remained unaltered with the liming treatments; some differences occurred only on the cortex central vascular ratio. The IAC 165 cultivar was the only one that did not respond to the limestone rates and that decreased the cortex/central vascular ratio. The liming decreased the plant manganese contents associated with the temporary soil flooding. There was also a decrease in phosphorus, potassium and zinc contents, but the nitrogen, calcium, magnesium, and iron contents increased. Shoot fresh matter yield was larger with dolomitic than with calcitic limestone for all cultivars, except IAC 47. All the cultivars showed higher magnesium and lower calcium contents in the shoots with dolomitic than with calcitic limestone. Although a positive yield response could not be obtained in the present study, it can be inferred that when upland rice is used in these soils for crop pasture renewals, dolomitic limestone might be recommended to correct acidity and magnesium deficiency in plant.

Index terms: upland rice, Oryza sativa L., root anatomy, calcium, magnesium.

\section{INTRODUÇÃO}

Os solos da região paulista do Médio Vale do Paranapanema são classificados, em sua maioria, como latossolo vermelho-escuro álico, textura média, e areias quartzosas, apresentando baixa capacidade de troca de cátions (CTC) e saturação por bases (Prado et al., 1999).
O arroz-de-sequeiro, Oryza sativa $\mathrm{L}$., tem sido cultivado nessas condições, principalmente em áreas de renovação de pastagens. Os cultivares IAC 25, IAC 47 e IAC 165, originados de progenitores comuns, são os mais empregados, apresentando-se o IAC 165, por ocasião do seu lançamento, 20 a $30 \%$ mais produtivo, respectivamente, do que o IAC 25 e o IAC 47 (Usberti Filho et al., 1987). 
Verificou-se, em trabalho anterior, que a calagem é uma prática necessária para prevenir o amarelecimento da cultura do arroz, em areia quartzosa. O amarelecimento ocorria sob condições de encharcamento e baixa fertilidade natural do solo, em vista da toxicidade de ferro e à deficiência de magnésio na planta, associadas a um múltiplo estresse nutricional. Observou-se, também, uma tolerância varietal do arroz-de-sequeiro ao amarelecimento; o cultivar Araguaia, originado do IAC 47, mostrou-se mais tolerante às condições adversas que induziram o aparecimento desses sintomas (Duarte et al., 1993).

Mesmo sendo o arroz considerado uma espécie adaptada às condições de acidez do solo, seus cultivares também diferem em suas respostas ao estresse de alumínio e à calagem (Fageria, 1982, e Ferreira et al., 1986). Ferreira et al. (1986) classificaram o 'IAC $47^{\prime}$ como tolerante ao alumínio e não responsivo à aplicação de calcário, enquanto o 'IAC 164', linhagem irmã do 'IAC 165', foi considerado sensível ao alumínio e responsivo à correção da acidez do solo. Furlani \& Furlani (1991) classificaram ambos os cultivares como eficientes na utilização do fósforo e tolerantes ao alumínio.

Poucos são os estudos sobre a resposta de cultivares de arroz à calagem e sobre as doses mais econômicas de calcário em solos arenosos, principalmente quando ocorrem problemas de estresse nutricional.

Objetivou-se, com o presente trabalho, estudar a resposta de cultivares de arroz-de-sequeiro à calagem em areia quartzosa e o efeito da calagem na estrutura radicular.

\section{MATERIAL E MÉTODOS}

Desenvolveu-se um ensaio em condição de campo, em Assis (SP), em areia quartzosa com $8 \%$ de argila, descrita por Prado et al. (1999). Utilizaram-se cinco doses de calcário e os quatro cultivares de arroz seguintes: IAC 25 e IAC 165 , de ciclo curto, e IAC 47 e Araguaia, de ciclo médio.

O delineamento experimental foi de parcelas subdivididas, com distribuição em blocos ao acaso e quatro repetições. As doses de calcário constituiram as parcelas e os cultivares, as subparcelas. Estas foram compostas por quatro linhas de $5 \mathrm{~m}$ de comprimento e espaçadas de $50 \mathrm{~cm}$, considerando-se para colheita $4 \mathrm{~m}$ das duas linhas centrais.

O calcário foi distribuído a lanço e incorporado com enxada manual a cerca de $20 \mathrm{~cm}$ de profundidade. O adubo, aplicado em sulcos na semeadura, constituiu-se de $10 \mathrm{~kg} \cdot \mathrm{ha}^{-1}$ de nitrogênio (sulfato de amônio), $60 \mathrm{~kg} \cdot \mathrm{ha}^{-1}$ de $\mathrm{P}_{2} \mathrm{O}_{5}$ (superfosfato simples) e $40 \mathrm{~kg} \cdot \mathrm{ha}^{-1}$ de $\mathrm{K}_{2} \mathrm{O}$ (cloreto de potássio); em cobertura, aplicaram-se $30 \mathrm{~kg} \cdot \mathrm{ha}^{-1}$ de nitrogênio na superfície do solo, na forma de sulfato de amônio, cerca de 30 dias após a emergência, e utilizaram-se $40 \mathrm{~kg} \cdot \mathrm{ha}^{-1}$ de sementes.

Em outubro de 1991, aplicaram as doses seguintes: 0, 2, 4 e 6 t.ha ${ }^{-1}$ de calcário dolomítico e 2 t.ha-1 de calcário calcítico; em outubro de 1992, aplicou-se 0,5 t.ha $^{-1}$ de calcário calcítico em todas as parcelas para obtenção de dados homogêneos, pois, na testemunha, a produção foi muito irregular no primeiro ano. Ambos os calcários eram finamente moídos, ou seja, passavam totalmente pela peneira ABNT no 50. O calcário dolomítico continha $31,8 \%$ de $\mathrm{CaO}$ e 18,2\% de $\mathrm{MgO}$ e o calcítico, 31,9\% de $\mathrm{CaO}$ e 2,0\% de $\mathrm{MgO}$. Semeou-se o arroz no primeiro decêndio de novembro de 1991 e de dezembro de 1992. No ano agrícola 1991/92, avaliou-se somente a produção de grãos. No ano seguinte, aos 20 dias após a emergência, amostrou-se a parte aérea das plantas para análise de macro- e de micronutrientes (Bataglia et al., 1978), e, aos 40 dias, amostrou-se raíz para estudos anatômicos; na maturação dos grãos, procedeu-se à colheita e avaliação da massa verde da parte aérea, incluindo as inflorescências.

Os estudos anatômicos de raiz foram realizados em amostras coletadas em duas plantas por parcela. Segmentos pequenos de raíz foram fixados em formaldeído-ácido acético-álcool etílico 50\% (F.A.A.50) (Johansen, 1940), desidratados em série alcoólico-etílica, incluídos em parafina e cortados em micrótomo rotativo com $12 \mu \mathrm{m}$ de espessura. Os cortes transversais foram corados com safranina - "alcian blue" (Gabrielli, 1992). A partir desses cortes, efetua- 
ram-se sete medições para cada planta, do raio do córtex e do cilindro vascular, com ocular micrométrica, estimando-se a razão entre essas medidas (C/CV). Por meio dela, puderam ser comparadas raízes em várias fases de desenvolvimento.

Em outubro de 1993, amostrou-se o solo na profundidade de $0-20 \mathrm{~cm}$, para fins de análise de rotina de fertilidade do solo de acordo com o método de Raij \& Quaggio (1983).

Todos os resultados foram submetidos à análise da variância, estudando-se o efeito da calagem, mediante a regressão polinomial, e dos cultivares, pelo teste de Tukey, ambos ao nível de 5\%. O efeito do tipo de calcário, na dose 2 t.ha-1, foi estudado por contraste ortogonal, também ao nível de $5 \%$.

\section{RESULTADOS E DISCUSSÃO}

No primeiro ano, a produção média de grãos foi de $811 \mathrm{~kg} \cdot \mathrm{ha}^{-1}$, com um coeficiente de variação bastante elevado e heterogeneidade dos dados, que, por essa razão não são apresentados e discutidos.
Apesar de baixa, tal produtividade está próxima à das lavouras cultivadas nesse tipo de solo na região do Médio Paranapanema, variando, geralmente, de 1 a 1,5 t.ha ${ }^{-1}$.

No segundo ano, até aproximadamente 30 dias da emergência do arroz, ocorreram chuvas freqüentes e abundantes que levaram ao encharcamento do solo. $\mathrm{O}$ ataque generalizado de fungos nas panículas depreciou a qualidade dos grãos (chochamento), inviabilizando sua colheita.

Os resultados de análise de solo indicaram aumento dos teores de cálcio, magnésio, soma e saturação por bases, com a aplicação de calcário (Quadro 1), porém o maior valor da saturação foi de $55 \%$ na dose 6 t.ha $^{-1}$, provavelmente pela intensa lixiviação do calcário aplicado. $\mathrm{Na}$ dose 2 t.ha $^{-1}$, o tratamento calcítico não proporcionou aumento do teor de magnésio no solo, ao contrário do dolomítico, que promoveu mais $\mathrm{Mg}$.

A média de produção de massa verde da parte aérea foi de $2.701 \mathrm{~kg}$.ha-1. O 'IAC 165 ' e o 'Araguaia', genótipos lançados mais recentemente, apresentaram as maiores produções de massa verde da parte aérea, quando comparados ao 'IAC 25' (Quadro 2).

Quadro 1. Resultado de análise de rotina de fertilidade do solo, na camada $0-20 \mathrm{~cm}$, em função das doses de calcário

\begin{tabular}{|c|c|c|c|c|c|c|c|c|c|c|}
\hline Doses de calcário $^{(1)}$ & $\mathrm{P}$ & M.O. & $\mathrm{pH}$ & $\mathrm{K}$ & $\mathrm{Ca}$ & $\mathrm{Mg}$ & $\mathrm{H}+\mathrm{Al}$ & S & $\mathrm{T}$ & $\mathrm{V}$ \\
\hline t.ha $\mathrm{a}^{-1}$ & $\mathrm{mg} \cdot \mathrm{dm}^{-3}$ & g.dm $m^{-3}$ & & & & \multicolumn{2}{|c|}{$-\mathrm{mmol}_{\mathrm{c}} \cdot \mathrm{dm}^{-3}$} & & & $\%$ \\
\hline $0 \ldots \ldots \ldots \ldots \ldots \ldots \ldots$ & 19 & 10 & 4,1 & 0,3 & 2 & 1 & 33 & 3 & 35 & 9 \\
\hline $2 \mathrm{E} \ldots \ldots \ldots \ldots \ldots \ldots \ldots$ & 17 & 10 & 4,2 & 0,4 & 5 & 1 & 30 & 6 & 36 & 18 \\
\hline $2 \ldots \ldots \ldots \ldots \ldots \ldots \ldots \ldots$ & 16 & 10 & 4,4 & 0,3 & 4 & 2 & 26 & 6 & 33 & 20 \\
\hline 4 & 17 & 10 & 4,7 & 0,4 & 7 & 4 & 23 & 12 & 34 & 36 \\
\hline $6 \ldots \ldots \ldots \ldots \ldots \ldots \ldots$ & 18 & 10 & 5,3 & 0,4 & 13 & 9 & 17 & 21 & 38 & 55 \\
\hline $\mathrm{F}^{(2)}(\mathrm{p}<0,05) .$. & ns & ns & $\mathrm{L}$ & ns & $\mathrm{L}$ & $\mathrm{L}$ & $\mathrm{L}$ & $\mathrm{L}$ & ns & $\mathrm{L}$ \\
\hline
\end{tabular}

(1) Calcário dolomítico (31,8\% de $\mathrm{CaO}$ e $18,2 \%$ de $\mathrm{MgO}$ ), exceto o 2E, que é calcítico (31,9\% de $\mathrm{CaO}$ e 2,0\% de $\mathrm{MgO}$ ).

(2) L: efeito linear significativo; ns: não significativo. 
Essa produção aumentou com as doses de calcário em todos os cultivares (resposta linear e/ou quadrática), exceto no IAC 165. Tais resultados divergem dos apresentados por Ferreira et al. (1986), que apontaram o 'IAC 47' como não responsivo à correção do solo. Isso pode estar relacionado ao fato de, na presente área, existir o problema de toxicidade de ferro e manganês (Duarte et al., 1993), o qual não foi mencionado no trabalho de Ferreira et al. (1986). Outro aspecto é que o comportamento da produção de massa verde da parte aérea do presente trabalho não coincide necessariamente com a produção de grãos.

$\mathrm{Na}$ ausência de calcário, os teores de manganês na parte aérea das plantas foram muito altos e os de magnésio muito baixos (Quadro 3), quando comparados aos resultados obtidos por Malavolta et al. (1981) em plantas do 'IAC 47', cultivadas em solução nutritiva. Nota-se, também, que o calcário dolomítico aumentou de maneira linear ou quadrática os teores de nitrogênio, cálcio, magnésio e ferro e reduziu os de fósforo, potássio, manganês e zinco na parte aérea das plantas de arroz (Quadro 3). Observa-se, ainda, no Quadro 1, que os teores de P, K e matéria orgânica não foram afetados pelos tratamentos. Por sua vez, o 'Araguaia' apresentou maiores teores de nitrogênio comparado ao 'IAC 25' e ao 'IAC 165' e menores teores de manganês em relação ao 'IAC 47' e 'IAC 165', corroborando com o trabalho de Duarte et al. (1993).

Verificou-se maior produção de massa verde da parte área quando se aplicou calcário dolomítico em comparação ao calcítico (Quadro 2). O primeiro corrige a deficiência de magnésio na planta, elemento que faz parte da molécula de clorofila, e atua como ativador das enzimas relacionadas com o metabolismo energético (Mengel \& Kirkby, 1979). Todos os cultivares mostraram maiores teores de magnésio e menores de cálcio na parte aérea no tratamento dolomítico em comparação ao calcítico (Quadro 3), embora a análise da amostra superficial do solo, efetuada no segundo ano da calagem, não tenha indicado diferenças sensíveis (Quadro 1).

Em vista da baixa fertilidade natural dessa areia quartzosa e do problema do estresse nutricional múltiplo sob condições de encharcamento temporário, a calagem deve ser feita mesmo para os cultivares menos responsivos a essa prática.

Quadro 2. Produção de massa verde da parte aérea de cultivares de arroz-de-sequeiro, em função de diferentes doses de calcário

\begin{tabular}{|c|c|c|c|c|c|}
\hline \multirow{2}{*}{ Doses de calcário ${ }^{(1)}$} & \multicolumn{5}{|c|}{ Massa verde da parte aérea } \\
\hline & Araguaia & IAC 25 & IAC 47 & IAC 165 & Média \\
\hline t.ha ${ }^{-1}$ & \multicolumn{5}{|c|}{ kg.ha ${ }^{-1}$} \\
\hline 0 & 2.004 & 1.411 & 1.959 & 2.535 & 2.026 \\
\hline $2 \mathrm{E} \ldots \ldots \ldots \ldots$ & 2.780 & 2.194 & 2.424 & 2.408 & 2.452 \\
\hline 2 & 3.606 & 2.645 & 2.551 & 3.124 & 2.836 \\
\hline 4 & 3.764 & 2.540 & 2.848 & 2.940 & 3.169 \\
\hline 6 & 2.966 & 2.538 & 3.323 & 3.456 & 3.022 \\
\hline Média ……........................ & $3.085 \mathrm{a}$ & $2.284 b$ & $2.670 \mathrm{ab}$ & $3.014 \mathrm{a}$ & - \\
\hline $\mathrm{F}^{(2)}(\mathrm{p}<0,05) \ldots \ldots \ldots \ldots$ & Q & Q & $\mathrm{L}$ & ns & Q \\
\hline
\end{tabular}


Quanto ao estudo anatômico, verificou-se que o 'IAC 165 ' foi o único cultivar que apresentou diferença na razão entre o córtex e o cilindro vascular em função da calagem, havendo uma razão menor entre essas medidas com a aplicação de doses mais altas de calcário (Quadro 4). A diminuição da razão C/CV tanto pode ter sido ocasionada por um decréscimo na espessura do córtex como por um aumento na espessura do cilindro vascular. Neste trabalho, não foi possível fazer comparações entre a espessura do córtex e a do cilindro vascular porque as medidas foram obtidas em posições diferentes em relação ao ápice, consistindo, portanto, em fases diferentes de desenvolvimento.

Entre os cultivares, não houve diferença significativa na razão $\mathrm{C} / \mathrm{CV}$ na ausência de calcário. $\mathrm{O}$
'Araguaia' revelou menor razão C/CV do que o 'IAC 47' na dose 2 t.ha ${ }^{-1}$ de calcário dolomítico, enquanto o 'IAC 165' mostrou valores menores nas doses 4 e 6 t.ha ${ }^{-1}$, quando comparado aos demais cultivares. $\mathrm{O}$ 'IAC 47' apresentou a razão C/CV maior do que os outros na dose 2 t.ha ${ }^{-1}$ de calcítico, e o 'IAC 165 ', a menor razão.

Como se pode observar na Figura 1, a estrutura anatômica permaneceu inalterada com a calagem. Numa raiz jovem de plantas de arroz, abaixo da epiderme, apresenta-se uma exoderme formada por três camadas: a mediana, de paredes suberizadas, limitada externamente por uma camada de células maiores do que as epidérmicas, e, internamente, por outra camada de células adjacentes ao córtex.

Quadro 3. Teores de nutrientes na massa seca da parte aérea em função do cultivar e da calagem

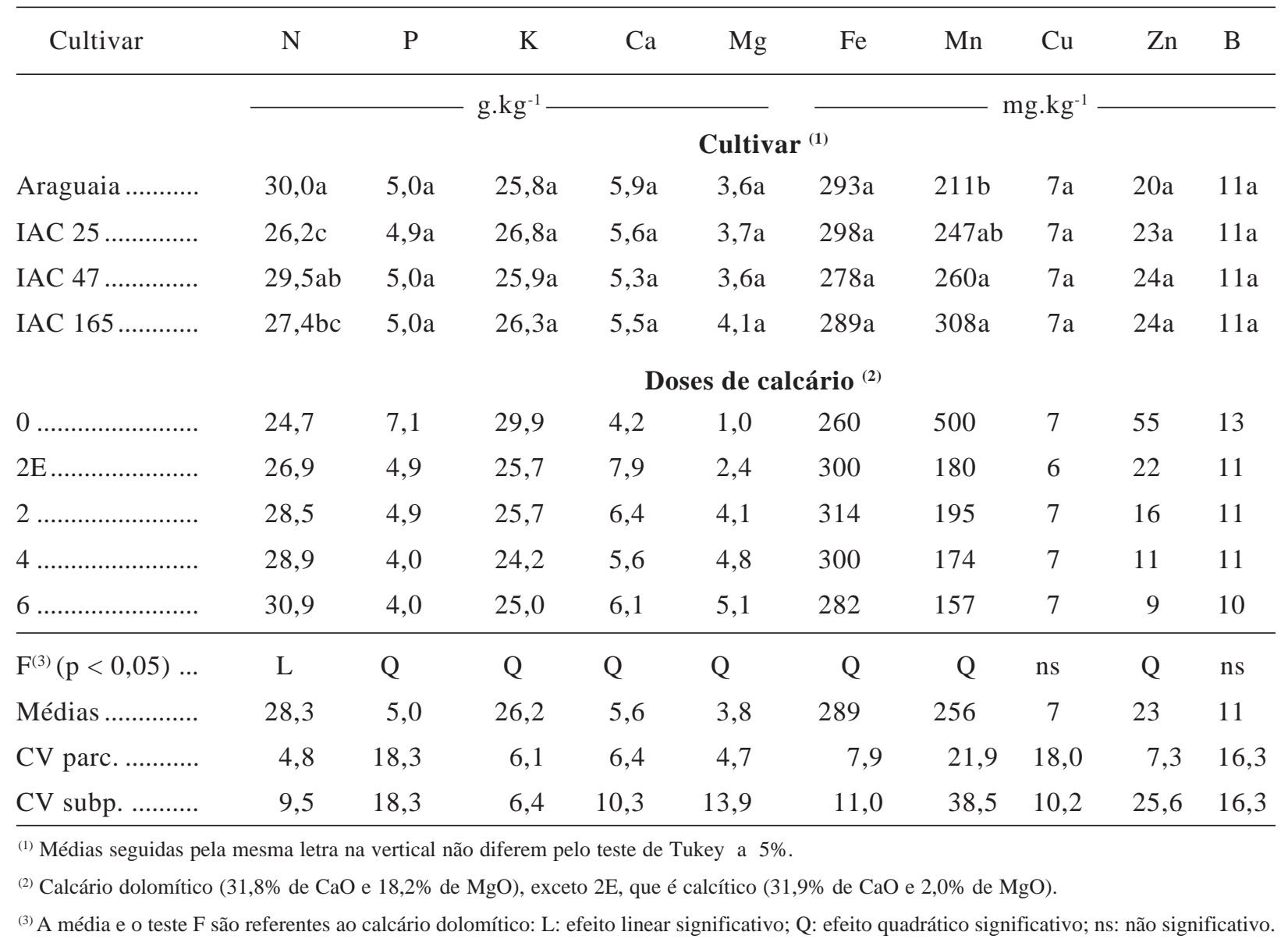



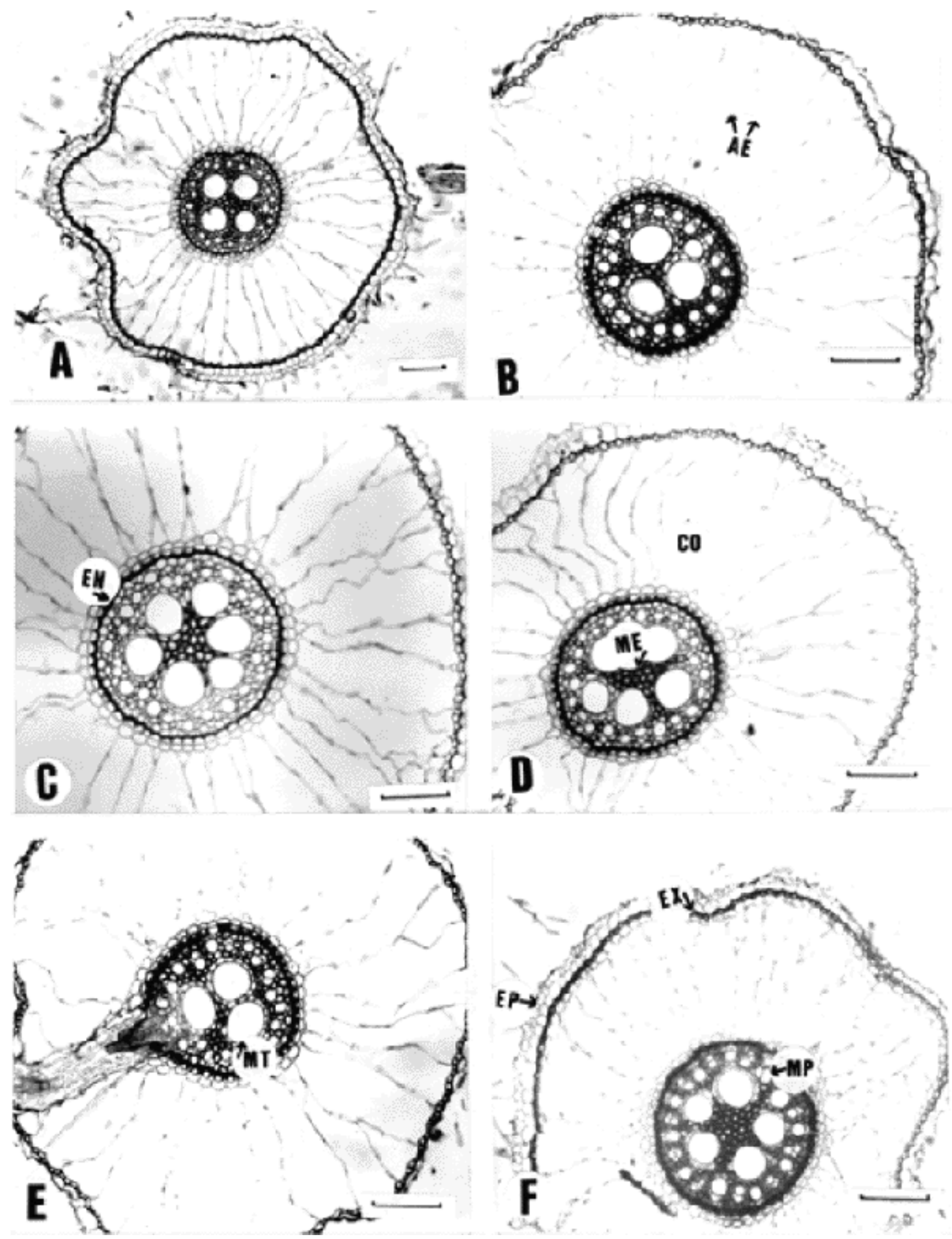

Figura 1. Seções transversais de raízes de plantas de arroz-de-sequeiro, 'IAC 165', desenvolvidas em solos submetidos a diferentes doses de calcário. A e E: 4 t.ha ${ }^{-1}$ de calcário dolomítico; B: 0 t.ha ${ }^{-1}$ de calcário dolomítico; C: 2 t.ha ${ }^{-1}$ de calcário dolomítico; D: 2 t.ha ${ }^{-1}$ de calcário calcítico; F: 6 t.ha ${ }^{-1}$ de calcário dolomítico. $\mathrm{AE}=$ aerênquima $\mathrm{CO}=$ córtex $; \mathrm{EN}=$ endoderme $; \mathrm{EP}=$ epiderme $; \mathrm{EX}=$ exoderme $; \mathrm{ME}=$ medula $; \mathrm{MP}=$ metaxilema precoce; $\mathrm{MT}=$ metaxilema tardio. $($ Barra da escala $=100 \mu \mathrm{m})$ 
Após a morte das células epidérmicas, a exoderme passa a ser o tecido de revestimento da raiz. Abaixo da exoderme, em direção ao cilindro vascular, há o córtex, formado por várias camadas de células parenquimáticas, que se degeneram com o amadurecimento da raiz, formando um aerênquima. Abaixo da camada mais interna do córtex, ocorre uma única camada de endoderme, seguida do periciclo, que, por sua vez, envolve o cilindro vascular. O centro da raiz é ocupado pela medula com o floema primário. As raízes jovens apresentam quatro elementos de vasos no metaxilema tardio; nas mais velhas, esse número permanece ou aumenta até seis. Os feixes de protoxilema e protofloema são numerosos, como um resultado da ausência de um crescimento secundário. $\mathrm{O}$ espessamento das células da medula começam após a formação do protoxilema, enquanto os elementos de vaso são ainda meristemáticos, no sentido centrífugo. Nas raízes maduras, todos os tecidos do cilindro vascular são espessados, exceto o periciclo e as células do floema, independentemente dos tratamentos.

A presença de um aerênquima na região cortical da raiz, como o que ocorre em plantas de arroz, tem sido atribuída a uma adaptação anatômica em plantas que se desenvolveram em ambientes úmidos ou relativamente áridos (Esau, 1977). Em arroz, constatou-se que a razão $\mathrm{C} / \mathrm{CV}$ aumenta com o encharcamento do solo (Duarte et al., 1993). O fato de o 'IAC 165' não ter apresentado um aumento da produção de massa verde da parte aérea e ter havido uma diminuição na razão $\mathrm{C} / \mathrm{CV}$ em doses maiores do que 2 t.ha ${ }^{-1}$ de calcário dolomítico, são indicativos de sua menor resposta à calagem nessa condição de encharcamento temporário do arroz-de-sequeiro.

Embora a máxima produtividade de massa verde tenha sido atingida, em média, com a dose calculada de 4,4 t.ha ${ }^{-1}$ de calcário dolomítico, a maior magnitude da resposta foi apenas de $87 \%$ em relação à testemunha, cuja produção foi relativamente baixa, indicando ser pouco provável a existência de retornos econômicos próximos à produtividade máxima. Acrescenta-se que ocorre uma redução acentuada dos teores de zinco na planta com o aumento das doses do calcário, o que pode explicar, em parte, o decréscimo da produção de massa do 'Araguaia' e do 'IAC 25' nas maiores doses de calcário, e a não-constatação de alterações anatômicas no sistema radicular.

De acordo com Cantarella \& Furlani (1997), deve-se recomendar calcário na cultura do arroz para atingir saturação por bases de $50 \%$ e teores de magnésio de $5 \mathrm{mmol}_{\mathrm{c}} \cdot \mathrm{dm}^{-3}$. Esse cálculo indica uma necessidade de 1,5 t.ha $^{-1}$ de calcário para o presente solo, mas, de acordo com os resultados, proporcionará valor de saturação por bases menor que o previsto.

Quadro 4. Médias da razão entre as medidas da espessura do córtex (C) e do cilindro vascular (CV) de raízes de plantas de arroz-de-sequeiro cultivadas com diferentes doses de calcário e significância do teste $\mathrm{F}$ para calagem

\begin{tabular}{|c|c|c|c|c|c|c|c|}
\hline \multirow{3}{*}{ Cultivar $^{(1)}$} & \multicolumn{6}{|c|}{$\mathrm{C} / \mathrm{CV}$} & \multirow{3}{*}{$\begin{array}{l}\text { Teste F } \\
(\mathrm{p}<0,05)\end{array}$} \\
\hline & \multicolumn{6}{|c|}{ Doses de calcário } & \\
\hline & 0 & $2 \mathrm{E}$ & 2 & 4 & 6 & Média & \\
\hline Araguaia ........... & $2,70 \mathrm{a}$ & $2,75 b$ & $2,61 b$ & $2,83 \mathrm{a}$ & $2,74 a$ & $2,72 b c$ & ns \\
\hline IAC $25 \ldots \ldots \ldots \ldots$ & $2,78 \mathrm{a}$ & $2,83 b$ & $2,76 a b$ & $3,17 \mathrm{a}$ & $2,87 \mathrm{a}$ & $2,90 \mathrm{ab}$ & ns \\
\hline IAC $47 \ldots \ldots \ldots \ldots$ & $2,88 \mathrm{a}$ & $3,05 \mathrm{a}$ & $3,00 \mathrm{a}$ & $2,91 \mathrm{a}$ & $2,93 a$ & $2,93 \mathrm{a}$ & ns \\
\hline IAC $165 \ldots \ldots \ldots$. & $2,70 \mathrm{a}$ & $2,40 \mathrm{c}$ & $2,83 \mathrm{ab}$ & $2,44 b$ & $2,35 b$ & $2,58 \mathrm{c}$ & $\mathrm{L}$ \\
\hline Média ................. & 2,76 & 2,75 & 2,80 & 2,84 & 2,73 & & ns \\
\hline
\end{tabular}


Talvez, a diferença seja devida à lixiviação de cátions nesse solo muito arenoso. Acrescente-se que, pelo critério do alumínio (dose calcário $=2 \times \mathrm{Al}$ ), se se considerar que o solo original apresentava teor de alumínio de 5,2 mmol $.100 \mathrm{~g}^{-1}$ na camada 0-20 $\mathrm{cm}$ (Prado et al., 1999), seria recomendável dose de calcário semelhante à do método anterior.

\section{CONCLUSÕES}

1. Independentemente de os genótipos de arroz-de-sequeiro diferirem quanto à resposta à calagem, nessas condições de baixa fertilidade natural do solo e toxicidade de manganês, deve-se aplicar calcário dolomítico para correção da acidez e fornecimento de magnésio às plantas de arroz.

2. A calagem modificou, em função do cultivar, a razão entre a medida do córtex e do cilindro vascular da raíz, porém a estrutura anatômica permaneceu inalterada.

\section{REFERÊNCIAS BIBLIOGRÁFICAS}

BATAGLIA, O.C.; TEIXEIRA, J.P.F.; FURLANI, P.R.; FURLANI, A.M.C. \& GALLO, J.R. Métodos de análise química de plantas. Campinas, Instituto Agronômico, 1978. 31p. (Circular, 87)

CANTARELLA, H. \& FURLANI, P.R. Arroz-de-sequeiro. In: RAIJ, B. van; CANTARELLA, H.; QUAGGIO, J.A. \& FURLANI, A.M.C., eds. Recomendações de adubação e calagem para o Estado de São Paulo. 2.ed., Campinas, Instituto Agronômico, 1997.p.48-49. (Boletim técnico, 100)

DUARTE, A.P.; VOLTAN, R.B.Q. \& FURLANI, P.R. Amarelecimento do arroz-de-sequeiro sob condições de encharcamento em solo de baixa fertilidade. Bragantia, Campinas, 52(2):139-152, 1993.
ESAU, K. Anatomy of seed plants. 2.ed. New York, John Wiley, 1977. 550p.

FAGERIA, N.K. Tolerância diferencial de cultivares de arroz e alumínio em solução nutritiva. Pesquisa Agropecuária Brasileira, Brasília, 17(1):1-9, 1982.

FERREIRA, R.P.; SALGADO, L.T. \& JORGE, H.D. Tolerância de cultivares de arroz ao alumínio. Pesquisa Agropecuária Brasileira, Brasília, 21(12):1257-1260, 1986.

FURLANI, P.R. \& FURLANI, A.M.C. Tolerância a alumínio e eficiência a fósforo em milho e arroz: características independentes. Bragantia, Campinas, 50(2):331-340, 1991.

GABRIELLI, A.C. Contribuição ao estudo anatômico da raiz de Pyrostegia venusta (ker) Miers-Bignociaceae. Revista Brasileira de Botânica, São Paulo, 15(2):95-104, 1992.

JOHANSEN, D.A. Plant microtechnique. New York, McGraw Hill, 1940. 523p.

MALAVOLTA, E.; SILVA, J.C.A.; RODRIGUES, T.E.; SABINO, J.C.; GOMES, I.A.; CRUZ, A.P.; OLIVEIRA, F.A.; DAGHLIAN, C.; GUERRINI, I.A.; MAZZA, J.A.; CORREA, L.S.; SCHIAVUZZO, M.A.; COSTA, M.P.; CABRAL, C.P.; DARIO, L.A.; ANTONIOLLI, F.C. \& PAVAN, L.H.S. Estudos sobre a nutrição mineral do arroz: VII. Exigências nutricionais das variedades IAC25 e IAC-47. Anais da Escola Superior de Agricultura “Luiz de Queiroz”, Piracicaba, 38(2):507-519, 1981.

MENGEL, K. \& KIRKBY, E.A. Principles of plant nutrition. 2.ed. Bern, International Potash Institute, 1979. 593p.

PRADO, H. do; TREMOCOLDI, W.A.; JORGE, J.A. \& MENK, J.R.F. Levantamento pedológico detalhado da Estação Experimental de Assis, SP. Campinas, Instituto Agronômico, 1999. (Documento técnico, no prelo.)

RAIJ, B. van \& QUAGGIO, J.A. Métodos de análise de solo para fins de fertilidade. Campinas, Instituto Agronômico, 1983. 31p. (Boletim técnico, 81)

USBERTI FILHO, J.A.; AZZINI, L.E.; TISSELLI FILHO, O.; SOAVE, J.; FURLANI, P.R.; GALLO, P.B.; PETTINELLI JÚNIOR, A.; CASTRO, J.L. de \& VITTI, P. Cultivar IAC-165 de arroz-de-sequeiro: comportamento agronômico, qualidades tecnológicas e culinárias. Campinas, Instituto Agronômico, 1987. 13p. (Boletim técnico, 115) 